\title{
Treatment of essential tremor: are there issues we are overlooking?
}

\author{
Elan D. Louis ${ }^{1,2,3,4 *}$ \\ 1 Gertrude H. Sergievsky Center, College of Physicians and Surgeons, Columbia University, New York, NY, USA \\ 2 Department of Neurology, College of Physicians and Surgeons, Columbia University, New York, NY, USA \\ ${ }^{3}$ Taub Institute for Research on Alzheimer's Disease and the Aging Brain, College of Physicians and Surgeons, Columbia University, New York, NY, USA \\ ${ }^{4}$ Department of Epidemiology, Mailman School of Public Health, Columbia University, New York, NY, USA
}

Edited by:

Marina Tijssen, Academic Medical

Centre, Netherlands

\section{Reviewed by:}

Pedro Chana, Universidad de Santiago de Chile, Chile

Bart Post, Radboud University

Nijmegen Medical Centre,

Netherlands

*Correspondence:

Elan D. Louis, Unit 198, Neurological Institute of New York, 710 West 168th Street, New York, NY 10032, USA. e-mail:EDL2@columbia.edu
Background: Essential tremor (ET) is one of the most common neurological diseases. Although a large number of medications have been tested, there are only two first-line medications, primidone and propranolol, which is a situation that has not changed in approximately 30 years. Several recent reviews have summarized the current pharmacotherapeutic options for ET and the approach to the management of ET patients. Yet there remain a number of important issues, both scientific and clinical, that have not been broached in the literature and that have therapeutic implications. Objectives: To introduce several clinical and scientific issues that have not formally entered the published literature on the treatment of ET. Methods: In September 2011, materials for this article were gathered during a literature search of PubMed using the following terms: ET, clinical, clinical trial, treatment, medications, therapeutics. English-language articles were selected for further review. Results: The paper focuses on several topics that have received scant or no discussion in the published literature on ET therapeutics. These topics are as follows: the nature of the underlying disease pathophysiology, the presence of pathological heterogeneity, the complexity of cellular and neurochemical changes which may be underlying this disorder, the presence of clinical heterogeneity, the selection of treatment endpoints, the effects of diagnostic uncertainty, the presence of cognitive and psychiatric features in ET, the identification of possible modifiable risk factors, and the absence of any neuroprotective therapies. Conclusion: The author has identified several topics that have received scant or no discussion in the published literature on ET therapeutics. Further discussion of the issues raised here may lead to improvements in clinical trial methodologies as well as facilitate the development of fresh approaches to pharmacotherapy.

Keywords: essential tremor, treatment, clinical, pharmacology

\section{INTRODUCTION}

Essential tremor (ET), a disease whose hallmark feature is action tremor of the hands, is one of the most common neurological diseases. It occurs in approximately $4.0 \%$ of individuals aged 40 years and older (Dogu et al., 2003) and its prevalence continues to rise with age, with prevalence estimates of $21.7 \%$ among persons aged 95 years and older (Louis et al., 2009c). The tremor is often progressive (Critchley, 1949) and patients may experience difficulties performing basic daily activities (Busenbark et al., 1991; Bain et al., 1994; Louis et al., 2001), thereby impairing quality of life (Troster et al., 2005). In addition to action tremor, patients may also have intention tremor (Louis et al., 2009b), rest tremor (Cohen et al., 2003), and other motor signs, including ataxia (Singer et al., 1994). More than $90 \%$ of patients who seek medical care report disability (Louis et al., 2001), and severely affected end-stage patients are unable to feed or dress themselves. Between 15 and $25 \%$ of patients are forced to retire prematurely, and $60 \%$ choose not to apply for a job or promotion because of uncontrollable shaking (Rautakorpi, 1978; Bain et al., 1994). There have been few studies of mortality; however, the one prospective study that also enrolled a control group reported a $45 \%$ increased risk of mortality (Louis et al., 2007b), suggesting that ET could be a disease of both increased morbidity and mortality. In addition to the presence of motor signs, a recent literature has documented the presence of non-motor manifestations as well. These include cognitive deficits and dementia (Troster et al., 2002; Benito-Leon et al., 2006a,b; Bermejo-Pareja et al., 2007), personality traits and depression (Chatterjee et al., 2004; Lorenz et al., 2006; Louis et al., 2007d).

The pharmacological treatment of ET is not optimal (Gironell, 2007). Although many medications have been tested, there are only two first-line medications, primidone and propranolol (Table 1; Zesiewicz et al., 2002, 2005; Benito-Leon and Louis, 2006, 2007), which is a situation that has not changed in approximately 30 years (Winkler and Young, 1971; Chakrabarti and Pearce, 1981). Furthermore, medications are often considered to be effective in only $50 \%$ of patients with this disease (Thanvi et al., 2006). Even when effective, medications rarely reduce the tremor to asymptomatic levels (Gironell et al., 1999) and they are often associated with troublesome side effects (e.g., somnolence, depression), so that many patients decide to discontinue them. For example, in one clinical 
Table 1 | Medications that have been evaluated in the treatment of ET (Zesiewicz et al., 2005; Benito-Leon and Louis, 2007; Lyons and Pahwa, 2008b; Deuschl et al., 2011).

\begin{tabular}{ll}
\hline First-line medications & Primidone \\
Additional medications & Propranolol \\
& Acetazolamide \\
& Alprazolam \\
& Atenolol \\
& Botulinum toxin \\
& Clonazepam \\
& Clozapine \\
& 3,4 -diaminopyridine \\
& Ethanol \\
& Gabapentin \\
Isoniazid \\
Levetiracetam \\
Nadolol \\
Nimodipine \\
Octanol \\
Olanzapine \\
Oxcarbazepine \\
Phenobarbital \\
Pindolol \\
Pregabalin \\
Sodium oxybate \\
Sotalol \\
Tiagabine \\
Topiramate \\
Trazodone \\
Zonegran \\
\end{tabular}

trial of primidone, a first-line medication, 7 of 11 patients $(63 \%)$ chose not to take the medication when the trial ended (Sasso et al. 1990). In a recent survey of more than 500 ET patients, nearly one in three had stopped taking medications for their tremor and a nearly identical proportion of ET patients with severe tremor also had discontinued medications (Louis et al., 2010). In sum, there is a sizable population of ET patients, many of whom have functional disability and impaired quality of life, who remain untreated. In recent years, a limited number of pharmacologically unresponsive patients have turned to deep-brain stimulation (DBS) and other surgeries to provide relief (Hubble et al., 1997; Hariz et al., 1998; Schuurman et al., 2000; Kondziolka et al., 2008). Several recent reviews have provided detailed accounts of the current pharmacotherapeutic options for ET (Zesiewicz et al., 2005; Benito-Leon and Louis, 2007; Lyons and Pahwa, 2008b; Deuschl et al., 2011). The goal of this paper is not to duplicate those reviews, but rather, to raise a number of clinical and scientific issues that have yet to formally enter the published literature on the treatment of ET and, in doing so, to further stimulate dialog in this field.

\section{METHODS}

In September 2011, materials for this article were gathered during a literature search of PubMed using the following terms: ET, clinical, clinical trial, treatment, medications, therapeutics. Relevant articles published before September 2011 were retrieved and only Englishlanguage articles were selected for further review. Based on this review, the author identified several topics that have received scant or no discussion in the published literature on ET therapeutics.

\section{RESULTS}

Based on the literature review, the author identified several topics that have received scant or no discussion in the published literature on ET therapeutics.

\section{TOPIC 1: WHAT IS THE NATURE OF THE DISEASE WE ARE TREATING?}

While appraising the current state of pharmacotherapy, it is important the one takes into consideration the nature of the underlying disease process and its pathophysiological underpinnings. Recent data, emerging from controlled studies of human postmortem tissue, indicate the presence of degenerative changes in ET brains (Louis et al., 2005, 2006a,b, 2007c; Louis and Vonsattel, 2007) In the large majority of cases, these changes occurred in the cerebellum (Louis et al., 2006a,b, 2007c; Louis and Vonsattel, 2007). These changes included swellings of Purkinje cell axons and dendrites, significant (approximately 30-40\%) death of Purkinje cells, heterotopic displacement of Purkinje cells (Kuo et al., 2011), remodeling of neighboring neurons (e.g., Basket cells; Louis and Vonsattel, 2007; Louis et al., 2007c; Axelrad et al., 2008; Louis, 2009; EricksonDavis et al., 2010), and, in some cases, more extensive degenerative changes in the cerebellum (Louis et al., 2006a). Many though not all of these changes have been observed to varying degrees in the brains of patients with spinocerebellar ataxias (SCAs), a group of diseases that, like ET, are strongly familial, progressive, and associated with intention tremor and ataxia (Koeppen, 2005). These postmortem data, along with the clinical picture of a disease process with insidious onset and progressive nature indicate that the disease is probably neurodegenerative in nature (Louis, 2009; Bermejo-Pareja, 2011).

Given a situation in which the root cause of the disease seems likely to be a progressive degeneration of neuronal tissue, what can one realistically expect of medications? The pharmacological treatment of the neurodegenerative diseases [e.g., Alzheimer's disease (AD), amyotrophic lateral sclerosis (ALS)] is, unfortunately, very limited (Henriksen et al., 2006; Klafki et al., 2006; Karran and Palmer, 2007; Zoccolella et al., 2009). There have been a small number of successes, but these are the exceptions rather than the rule. One is that of Parkinson's disease (PD), in which the pharmacological replacement of brain dopamine provides temporary relief of some but not all motor symptoms (Diaz and Waters, 2009), although this relief is time-limited, and the treatment of PD-related cognitive decline has not been successful. Another is Huntington's disease (HD), in which pharmacological manipulation of brain dopamine production, release and post-synaptic binding provides some relief from chorea (Cardoso, 2009), although not for the progressive cognitive and personality changes or incoordination that accompany this relentlessly progressive disorder.

Perhaps more pertinent for ET is the SCAs, for reasons noted above. The symptomatic treatment of the SCAs is also very limited. The most prominent feature, ataxia, is very difficult to manage; 
there are no clearly effective treatments available, and no FDAapproved medications for this symptom (Fogel and Perlman, 2006). It is within this broader context that one must conceptualize the treatment of ET and the challenging task of developing effective pharmacotherapeutic options.

While considering pathophysiology, there is one other issue that merits attention, and this is the issue of pathological heterogeneity. Although the majority of ET cases have degenerative changes in the cerebellum, this is not true of all cases. In some postmortem studies, a smaller sub-set has been reported to have other degenerative changes in the form of brainstem Lewy bodies (Louis and Vonsattel, 2007; Louis et al., 2007c). Hence, postmortem studies indicate the likely presence of pathological heterogeneity, with several different tissue-based subtypes of ET having been identified thus far (Louis and Vonsattel, 2007; Louis et al., 2007c). These postmortem observations are likely to be relevant to the treatment of ET. A reoccurring finding in many pharmacotherapeutic trials of ET is that the response to medication is usually mixed, with approximately one-third to one-half of the patients showing a moderate degree of tremor reduction and the other patients demonstrating little or no response at all (Gironell et al., 1999). One possibility is that this heterogeneity of clinical response is a marker of different underlying disease mechanisms in subsets of patients. If ET is a heterogeneous family of diseases rather than a single clinical-pathological entity (Louis, 2009), then one set of therapies is not likely to be effective in all cases. In other words, therapeutic response phenotype is likely to be dependent on underlying pathological subtype.

\section{TOPIC 2: DO WE KNOW HOW CURRENT TREATMENTS ARE WORKING?}

Clinical updates on tremor generally divide treatments into firstline vs. second-line medications, with the former having more demonstrable efficacy (Table 1; Zesiewicz et al., 2005; BenitoLeon and Louis, 2007; Lyons and Pahwa, 2008b). Long lists of second-line medications provide a catalog of drugs that have been tried and have either failed or only been partly successful (Zesiewicz et al., 2005; Benito-Leon and Louis, 2007; Lyons and Pahwa, 2008b). A mixture of possible mechanisms of action is briefly noted for some of the listed medications and for others, none at all. What is missing, however, is a broad and unifying discussion of the probable mechanism of action of these medications.

Aside from the beta blockers, whose mechanism of action in ET is related to antagonism of peripheral beta-adrenergic receptors in muscle, a unifying feature of the large majority of medications that are used in the treatment of ET (e.g., primidone, phenobarbital, gabapentin, topiramate, benzodiazepines, sodium oxybate, ethanol, and octanol) is that they enhance gamma amino-butyric acid (GABA)-ergic tone in the central nervous system (Rincon and Louis, 2005). In addition to the observed reduction in Purkinje cells in ET (Louis et al., 2007c; Axelrad et al., 2008; Shill et al., 2008), low cerebrospinal fluid GABA levels have also been observed in patients with ET (Mally and Baranyi, 1994; Mally et al., 1996). The neurotransmitter of Purkinje cells is GABA, and the effect of the cerebellum through Purkinje cell output is modulatory or inhibitory. A decrease in the number or function of
Purkinje cells would result in reduced inhibitory cerebellar outflow and over-excitation. DBS is an effective surgical treatment for ET (Schuurman et al., 2000; Pahwa et al., 2001; Kluger et al., 2009); although its mechanism of action is not fully known, a number of possibilities have been discussed (Ushe et al., 2004), and one might be an alteration in abnormal cerebellar-thalamic outflow, which is involved not only in the generation and propagation of ET tremor but more broadly of rest tremor in PD (Helmich et al., 2011).

While attempts to increase central GABA-ergic tone have resulted in limited success in the treatment of ET, a more sophisticated approach to this problem has yet to be devised. Although GABA is the inhibitory transmitter of Purkinje cells, it is also the transmitter of other neurons in the cerebellum, including the Golgi cells and Basket cells. Basket cells are GABA-ergic inhibitory interneurons found in the molecular layer; they send out axonal collaterals to form a pericellular basket around the Purkinje cell body (Erickson-Davis et al., 2010). Recent study has found that basket cell processes are increased in ET, perhaps as a secondary remodeling response to Purkinje cell loss (Erickson-Davis et al., 2010). It is not clear how the peripheral administration of drugs that grossly elevate GABA-ergic tone influences this complex, multi-neuronal, GABA-ergic network in the cerebellum. Current experience (Thompson et al., 1984; Pahwa et al., 1998; Ondo et al., 2006; Zesiewicz et al., 2007), however, suggests that the effects of simply increasing GABA-ergic tone are mixed and varied. The issue deserves more critical scrutiny.

\section{TOPIC 3: THE “ONE SIZE FITS ALL” APPROACH: IS IT TIME TO MOVE BEYOND THIS?}

As noted above, recent postmortem studies suggest an underlying mechanistic heterogeneity for ET. One may approach the issue of heterogeneity from a clinical vantage point as well (Table 2). Among clinicians and clinical trialists, the traditional approach to the treatment of ET has largely been to regard ET patients as a single, homogeneous group. Perhaps the only exception is the occasional separation of patients with head tremor from those with upper limb tremor (Obwegeser et al., 2000; Song et al., 2008). The "one size fits all" approach is potentially problematic for several reasons. For example, this approach likely increases the occurrence of Type II errors in clinical trials (i.e., failing to reject the null hypothesis when there is a treatment effect). In clinical trials

Table 2 | Sources of clinical and pharmacological heterogeneity in ET.

\begin{tabular}{|c|c|}
\hline Feature & Comment \\
\hline Head tremor & $\begin{array}{l}\text { May be less responsive to medications than arm tremor } \\
\text { (Song et al., 2008) }\end{array}$ \\
\hline Voice tremor & $\begin{array}{l}\text { May be less responsive to medications than arm tremor } \\
\text { (Lyons and Pahwa, 2008a) }\end{array}$ \\
\hline $\begin{array}{l}\text { De novo vs. } \\
\text { previously } \\
\text { treated }\end{array}$ & $\begin{array}{l}\text { Previously treated patients may be less responsive to } \\
\text { medications, although no data directly address this issue }\end{array}$ \\
\hline $\begin{array}{l}\text { Short duration vs. } \\
\text { long duration ET }\end{array}$ & $\begin{array}{l}\text { Longer duration could be less responsive to } \\
\text { medications, although no data directly address this issue }\end{array}$ \\
\hline
\end{tabular}


in ET, one rarely distinguishes between de novo patients and previously treated patients; the two are generally lumped together and data are not presented on the mix of these cases entering the trial. Previously treated patients are generally self-selected to have been non-responsive to multiple previously tried medications and they are not ideal candidates for the testing of new therapies. Although this group of cases is often very motivated to find a treatment that is effective for them, their enrollment may falsely lead to the rejection of therapies that are potentially efficacious. At the very least, there is a need for clinical trials to report the number of de novo vs. previously treated patients and to analyze results separately for these two groups. An additional consideration is that it is important to distinguish between short-term response and longer-term response in clinical trials.

Another problem with the "one size fits all" approach is that patients may have a wide range of underlying disease durations. Longer duration disease in ET is associated with additional signs of cerebellar degeneration, including intention tremor (Louis et al., 2009b) and ataxic gait (Stolze et al., 2001), suggesting that long duration disease could be accompanied by more degenerative changes in the cerebellum and hence, a different brain substratum on which to apply pharmacotherapeutic interventions. In other words, the degree to which the underlying pathophysiological (i.e., tissue-based) changes have advanced is likely to influence the magnitude of therapeutic response. For example, in PD, advances in underlying Lewy body pathology are the likely underpinnings for end-stage, levodopa refractory disease (i.e., loss of the levodopa motor response; Apaydin et al., 2002).

\section{TOPIC 4: MAKING SENSE OF THE DATA: MULTIPLE TREATMENT EFFICACY ENDPOINTS}

To the new comer, making sense of the data in various treatment trials can be challenging. One issue is that clinical trials often utilize a confusing mélange of treatment endpoints and, furthermore, they present data in which therapeutic efficacy is found for some endpoints yet not for others. These endpoints may be broadly divided into four types: patient's subjective self-ratings, clinician's ratings, performance-based tests of function, and accelerometry (Table 3). While the first of these is subjective, the remaining three are objective, making them preferable. Accelerometry is the most precise and the most objective endpoint, yet the clinical correlates of accelerometric-measured changes can be unclear. For example, does a $25 \%$ reduction in tremor amplitude, as measured by accelerometry, necessarily translate into a clinically relevant functional change for the patient? What relative change as well as absolute final value is indicative of clinically meaningful pharmacotherapeutic efficacy? Clinician's ratings, which by their very nature are clinically grounded, generate values that are ordinal (i.e., $3>2>1$ ) but the difference between any two values is not necessarily the same (i.e., they are not interval values like the degrees on a thermometer). Also, they may not be sensitive to small changes. Hence, in many ways, performance-based tests of function provide the best alternative. First, they are objective assessments of function and second, they offer clinically and functionally relevant assessments of tremor. The ordinal rather than interval nature of the values that are used is a limitation.

The current state of affairs is that many tremor trials use a small number of these endpoints while others present data on all four. Performance-based tests are not always used. Many trials do not specify primary vs. secondary endpoints, so that the interpretation of the results, which is often mixed because the various endpoints assess different properties of tremor, is left to the reader. As a community, clinical trialists in ET should agree on the optimal methods for the uniform presentation of data. Indeed, it would be important to derive a core set of measures to be performed in each treatment trial of ET, so that pooling of data can be performed and more reproducible results for treatment of ET can be reported.

\section{TOPIC 5: ARE WE OVERLOOKING IMPORTANT TREATMENT ENDPOINTS?}

As noted above, one issue is understanding the assortment of endpoints that are currently being used in clinical trials. Another issue is whether we are identifying and routinely evaluating all of the potentially important endpoints. Each of the endpoints discussed above assessed tremor severity. Perhaps an equally important issue in ET is embarrassment. Embarrassment is a common feature in ET. In a recent study (Louis and Rios, 2009), 58.2\% of ET cases seen in a clinical setting reported embarrassment. Embarrassment is not only prevalent, but a major motivator for treatment (Louis and Rios, 2009). Anecdotal experience indicates that it is

Table 3 | Treatment efficacy endpoints in ET.

\begin{tabular}{|c|c|c|}
\hline & Advantages & Disadvantages \\
\hline \multirow[t]{2}{*}{ Patient's subjective self-rating } & Reflects the patient's own perception & Completely subjective \\
\hline & Clinically meaningful & Difficult to quantify \\
\hline \multirow[t]{4}{*}{ Clinician's rating } & Objective & Does not generate interval data \\
\hline & Clinically grounded & May not be sensitive to small changes \\
\hline & Incorporates clinical experience & \\
\hline & Easily administered & \\
\hline \multirow[t]{3}{*}{ Performance-based test of function } & Objective & Does not generate interval data \\
\hline & Assesses functionally relevant items & \\
\hline & Easily administered & \\
\hline \multirow[t]{3}{*}{ Accelerometry } & Objective & Clinical meaning is intrinsically unclear \\
\hline & Precise & More difficult to administer \\
\hline & Generates interval data & \\
\hline
\end{tabular}


one of the major reasons why patients seek treatment (BenitoLeon and Louis, 2007) and the study in New York found that the experience of embarrassment nearly doubled the odds of using tremor medication (Louis and Rios, 2009). Despite its importance, embarrassment is not routinely assessed in clinical trials nor is decline in embarrassment reported as a treatment endpoint. An embarrassment questionnaire for ET patients has recently been developed and validated (Traub et al., 2010); the questionnaire could be used in clinical trials and clinical settings to assess changes in level of embarrassment.

Another issue is quality of life. This issue has only come to the forefront in recent surgical trials (Troster et al., 1999; Hariz et al., 2002, 2008) and the development of an ET-specific instrument (Troster et al., 2005) paves the way for future examination of this issue.

\section{TOPIC 6: DIAGNOSTIC MISCLASSIFICATION: A LIKELY SOURCE FOR LOW PHARMACOLOGICAL RESPONSE RATES}

As noted above, one potential source of low pharmacological responsiveness in clinical trials is the enrollment of previously treated rather than de novo patients. Another source, both in clinical trials and in routine clinical practice, is diagnostic misclassification. Studies in both England and the United States have shown that $30-50 \%$ of ET cases are misdiagnosed (i.e., they frequently have other diseases such as PD or dystonia; Table 4; Schrag et al., 2000; Jain et al., 2006). The explanation is not clear yet one contributor may be that ET is often still regarded as a single, relatively featureless, neurologic sign. This is not the case. Among a host of other characteristics, the relative severity of different tremor types (kinetic more severe than postural; Brennan et al., 2002), the favored sites of anatomical involvement (arm more often than head, head more often than jaw; Louis et al., 2003), and the typical direction of spread over time (from arms to head rather than the converse; Louis, 2009) are distinctive, adding a degree of subtlety and complexity to the recognition and diagnosis of a disorder that is often viewed as relatively ordinary and featureless (Louis, 2009). In addition, the presence of other elements (e.g., postural tremor predominated by finger rather than wrist flexion, postural tremor manifesting mainly as thumb-flexion, re-emergent nature of postural tremor, dystonic posturing in tremulous limbs), which suggest the alternative diagnoses of PD or dystonia, are often not appreciated. Perhaps owing to a lack of familiarity with these features, misdiagnosis is exceedingly common. Regardless of the root cause, this high level of misdiagnosis suggests that ET, aside from being one of the most common neurological disorders, might be one of the most commonly misdiagnosed neurological disorders, with over application of the diagnosis being the main

Table 4 | Essential tremor: common misdiagnoses.

\begin{tabular}{lll}
\hline Study & Jain et al. (2006) & Schrag et al. (2000) \\
\hline $\begin{array}{ll}\text { True diagnoses } \\
\text { of "ET" }\end{array}$ & Parkinson's disease & Dystonic tremor \\
patients & Dystonic tremor & Neuropathic tremor \\
& Myoclonus dystonia & Drug-induced tremor \\
& Primary writing tremor & Post-traumatic tremor \\
& Enhanced physiological tremor &
\end{tabular}

problem. Consensus criteria (Deuschl et al., 1998) were proposed for ET more than a decade ago; despite this, a number of different diagnostic schemes for ET have been proposed and are in common use (Louis et al., 1997; Deuschl et al., 1998; Bain et al., 2000; Elble, 2000).

Another contributor to misdiagnosis is the ambiguity perpetuated by current diagnostic codes. Although there is an International Classification of Diseases (ICD) code for tremor (333.1), there is no specific ICD code for ET (Louis et al., 2007a). There is no unique code for several common tremor conditions, including enhanced physiological tremor, psychogenic tremor, orthostatic tremor, and drug-induced tremor. As a result, there is a tendency to lump a wide variety of different types of action tremor together. Given the very high rate of diagnostic misclassification, which is further exacerbated by ambiguity in the current ICD coding system, clinicians should be asking themselves whether they have the correct diagnosis before embarking on a treatment course for ET. Diagnostic misclassification is likely to be a source of low pharmacological response. If a clinician is treating PD or dystonia cases with ET medications, these "ET cases" are not likely to respond to these medications.

\section{TOPIC 7: PERSONALITY CHARACTERISTICS IN ET: COULD THESE INFLUENCE TREATMENT?}

Certain personality characteristics have been linked with neurological disorders. A rigid and introverted personality type has been suggested as possibly associated with $\mathrm{PD}$, and $\mathrm{PD}$ patients have been described as industrious, punctual, inflexible, cautious, and lacking in novelty seeking (Menza, 2000; Ishihara and Brayne, 2006; Macias et al., 2008). Whether and to what extent such traits are pre-morbid or disease-associated is not clear. HD patients, on the other hand, are often disinhibited and engage in more risktaking behaviors (Stout et al., 2001). The neural basis for these observations is unclear but could involve alterations within neurotransmitter systems (e.g., dopamine). Personality changes have also been noted in patients with spinocerebellar ataxia as well (Leroi et al., 2002). A tendency for certain personality features has been noted in ET. A study in New York (Chatterjee et al., 2004) reported higher harm avoidance scores in ET patients than controls. People who are more harm avoidant tend to be worrying, pessimistic, fearful, and doubtful rather than relaxed, optimistic, bold, and confident. Perhaps similarly, a study in Germany, which used a standardized personality inventory, noted that their patients with ET were kinder, more tender-minded, and less aggressive when compared with population controls (Lorenz et al., 2006), although the two studies used different personality inventories, making comparisons difficulty. Whether these features are premorbid, an early sign of morbidity, a later sign of morbidity, or a response to morbidity is not known. Regardless, the presence of personality features in ET, or any other disease, could have repercussions in terms of treatment, influencing the types of health care choices that patients make. For example, it has been pointed out that although ET is many times more prevalent than PD, the number of ET patients who are seriously impaired by their tremor who reach a DBS clinic for consideration of surgery is curiously very small, and perhaps as few as one-third of those being evaluated for surgery for PD (Young, 2002). A number of factors could underlie 
this observation. One is the slow rate at which ET develops and the tendency for patients with severe ET to modify and then gradually give up certain activities, thereby accommodating to some extent to their illness. Another explanation, however, may be a disease-related tendency toward harm avoidant behavior. Further evaluation of this issue is needed, but it is possible that the features of the disease itself influence the manner in which treatment is approached and accepted.

\section{TOPIC 8: COGNITIVE IMPAIRMENT IN ET: WHAT ARE THE THERAPEUTIC IMPLICATIONS?}

Many of the neurodegenerative diseases (e.g., AD, PD, HD) manifest as mixed cognitive-motor disorders. In these disorders, the underlying anatomic pathologies are widespread in the brain, involving both motor and cognitive areas. Disorders such as PD that canonically were defined as purely motor, are now known to have cognitive and psychiatric manifestations (Stern et al., 1993). Also, an individual with one of these disorders is probably at increased risk of developing another (the concept of increased tissue vulnerability, with examples including the increased cooccurrence in certain individuals of $\mathrm{PD}$ and $\mathrm{AD}$, Mayeux et al., 1988; ET and PD, Tan et al., 2008; Benito-Leon et al., 2009; ET and AD, Benito-Leon et al., 2006a; Bermejo-Pareja et al., 2007; Thawani et al., 2009), so that these disorders can co-occur in the same individual. There is an emerging literature documenting cognitive impairment and dementia in ET patients (Gasparini et al., 2001; Lombardi et al., 2001; Troster et al., 2002; Benito-Leon et al., 2006a,b; Bermejo-Pareja et al., 2007; Thawani et al., 2009).

What are the clinical implications for ET? First, the presence of cognitive impairment likely limits the maximum tolerable dose of medications, and especially those medications with known cognitive side effects. Hence, the maximum attainable dose is lower than in patients without cognitive impairment or dementia.

Second, these cognitive problems, in their own right, should probably be a target for therapeutic intervention. Clinicians should begin to assess whether the cognitive problems in their ET patients reflect a diagnosis of mild cognitive impairment or dementia rather than dismissing the problem as merely due to old age. If a diagnosis of dementia is assigned, then what are the best treatments for ET-related dementia? To some extent, this depends on the underlying nature of the dementia which occurs in ET patients. There are few data, yet clinical-epidemiological studies suggest that it is AD (Benito-Leon et al., 2006a; Bermejo-Pareja et al., 2007; Thawani et al., 2009). The use of AD medications has not been formally explored in ET patients who have dementia.

\section{TOPIC 9: NEUROPROTECTIVE THERAPY AND MODIFIABLE RISK FACTORS IN ET: BEGINNING A DIALOG}

The exploration of new medications for ET is focused exclusively on symptomatic therapies (Lee et al., 2003; Shill et al., 2004; Bushara et al., 2005; Gironell et al., 2006, 2008; Ondo et al., 2006; Handforth et al., 2009). With evidence from clinical, neuroimaging, and postmortem studies indicating that ET is likely to be a neurodegenerative disease (Louis, 2009), several questions arise. First, are there ways in which one can alter and slow the progression of the disease, and second, is there a mechanism to prevent the onset of disease?
Exploration of neuroprotective therapies has been ongoing in PD (Kieburtz and Ravina, 2007; Voss and Ravina, 2008; Hart et al., 2009) and HD (Emerich, 2001; Hersch and Rosas, 2008) for decades yet there have been no such trials in ET. The cellular changes that underlie ET are just now beginning to be elucidated and new knowledge should provide insights into the molecular mechanisms that underlie this disorder. Such insights could form the biologically based rationale for testing neuroprotective agents.

Modifiable risk factors have been identified for numerous neurological and systemic diseases (Booya et al., 2005; Reynolds et al., 2007; Di Pauli et al., 2008; Rains, 2008; Arima, 2009; Kotseva et al., 2009; Ovbiagele, 2010). These factors are extremely important because they form the backbone of primary prevention. There has been little discussion of these in ET. In a recent prospective, population-based study in central Spain (Louis et al., 2009a), lifetime ethanol consumption was assessed at baseline in 3,285 elderly participants, of whom 76 developed incident ET by followup. With each higher drink-year quartile, the risk of incident ET increased an average of $23 \%$, and the highest quartile was associated with twice the risk of incident ET. Ethanol is a well-established cerebellar toxin, resulting in Purkinje cell loss (Karhunen et al., 1994; Ramadoss et al., 2007; Dlugos, 2008). As noted above, recent postmortem studies have found pathological changes, including Purkinje cell loss, in the cerebellum in ET (Louis et al., 2007c; Axelrad et al., 2008; Shill et al., 2008) Ethanol, which is often used for symptomatic relief of ET (Benito-Leon and Louis, 2007), could be a continued source of underlying cerebellar neurotoxicity in patients who already manifest this disease. In sum, ethanol consumption might be a modifiable risk factor in ET and minimization of ethanol consumption in ET patients could alter the course of progression. Furthermore, minimization in at-risk individuals could delay the onset of the illness. Further studies are clearly needed, but these initial data at least open the possibility that disease course could be modified in ET.

One study found that baseline heavy cigaret smoking was associated with a lower risk of incident ET (Benito-Leon et al., 2008). The adverse health effects associated with smoking; however, do not make this a practical approach to lowering risk of ET.

\section{DISCUSSION}

In this review, a number of clinical and scientific issues were raised that are relevant to the treatment of ET. These include issues of underlying disease pathophysiology, the presence of pathological heterogeneity, the complexity of the cellular and neurochemical changes which may be underlying this disorder, the presence of clinical heterogeneity, selection of treatment endpoints, the effects of diagnostic uncertainty, the presence of cognitive and psychiatric aspects to the disease, and the identification of possible modifiable risk factors, and the absence of any neuroprotective therapies. It is hoped that further discussion of these issues will lead to improvements in clinical trial methodologies and clinical practice, as well as facilitate the development of newer therapies for this common neurological disease.

\section{ACKNOWLEDGMENTS}

NIH NS039422 and NIH NS042859 and the Parkinson's disease foundation. 


\section{REFERENCES}

Apaydin, H., Ahlskog, J. E., Parisi, J. E., Boeve, B. F., and Dickson, D. W. (2002). Parkinson disease neuropathology: later-developing dementia and loss of the levodopa response. Arch. Neurol. 59, 102-112.

Arima, H. (2009). Blood pressurelowering treatment for primary and secondary prevention of different types of stroke. Expert Rev. Cardiovasc. Ther. 7, 627-636.

Axelrad, J. E., Louis, E. D., Honig, L. S., Flores, I., Ross, G. W., Pahwa, R., Lyons, K. E., Faust, P. L., and Vonsattel, J. P. (2008). Reduced Purkinje cell number in essential tremor: a postmortem study. Arch. Neurol. 65, 101-107.

Bain, P., Brin, M., Deuschl, G., Elble, R., Jankovic, J., Findley, L., Koller, W. C., and Pahwa, R. (2000). Criteria for the diagnosis of essential tremor. Neurology 54, S7.

Bain, P. G., Findley, L. J., Thompson, P. D., Gresty, M. A., Rothwell, J. C., Harding, A. E., and Marsden, C. D. (1994). A study of hereditary essential tremor. Brain 117( $\mathrm{Pt} 4)$, 805-824.

Benito-Leon, J., and Louis, E. D. (2006). Essential tremor: emerging views of a common disorder. Nat. Clin. Pract. Neurol. 2, 666-678.

Benito-Leon, J., and Louis, E. D. (2007). Clinical update: diagnosis and treatment of essential tremor. Lancet 369, 1152-1154.

Benito-Leon, J., Louis, E. D., and Bermejo-Pareja, F. (2006a). Elderlyonset essential tremor is associated with dementia. Neurology 66 1500-1505.

Benito-Leon, J., Louis, E. D., and Bermejo-Pareja, F. (2006b). Population-based case-control study of cognitive function in essential tremor. Neurology 66, 69-74.

Benito-Leon, J., Louis, E. D., and Bermejo-Pareja, F. (2008). Population-based case-control study of cigarette smoking and essential tremor. Mov. Disord. 23, 246-252.

Benito-Leon, J., Louis, E. D., and Bermejo-Pareja, F. (2009). Risk of incident Parkinson's disease and parkinsonism in essential tremor: a population based study. J. Neurol. Neurosurg. Psychiatr. 80, 423-425.

Bermejo-Pareja, F. (2011). Essential tremor - a neurodegenerative disorder associated with cognitive defects? Nat. Rev. Neurol. 7, 273-282.

Bermejo-Pareja, F., Louis, E. D., and Benito-Leon, J. (2007). Risk of incident dementia in essential tremor: a population-based study. Mov. Disord. 22, 1573-1580.

Booya, F., Bandarian, F., Larijani, B., Pajouhi, M., Nooraei, M., and Lotfi, J. (2005). Potential risk factors for diabetic neuropathy: a case control study. BMC Neurol. 5, 24. doi:10.1186/1471-2377-5-24

Brennan, K. C., Jurewicz, E. C., Ford, B., Pullman, S. L., and Louis, E. D. (2002). Is essential tremor predominantly a kinetic or a postural tremor? A clinical and electrophysiological study. Mov. Disord. 17, 313-316.

Busenbark, K. L., Nash, J., Nash, S., Hubble, J. P., and Koller, W. C. (1991). Is essential tremor benign? Neurology 41, 1982-1983.

Bushara, K. O., Malik, T., and Exconde, R. E. (2005). The effect of levetiracetam on essential tremor. Neurology 64, 1078-1080.

Cardoso, F. (2009). Huntington disease and other choreas. Neurol. Clin. 27 719-736.

Chakrabarti, A., and Pearce, J. M. (1981). Essential tremor: response to primidone. J. Neurol. Neurosurg. Psychiatr. 44, 650.

Chatterjee, A., Jurewicz, E. C., Applegate, L. M., and Louis, E. D. (2004). Personality in essential tremor: further evidence of non-motor manifestations of the disease. J. Neurol. Neurosurg. Psychiatr. 75, 958-961.

Cohen, O., Pullman, S., Jurewicz, E., Watner, D., and Louis, E. D. (2003). Rest tremor in patients with essential tremor: prevalence, clinical correlates, and electrophysiologic characteristics. Arch. Neurol. 60, 405-410.

Critchley, M. (1949). Observations of essential (heredofamilial) tremor. Brain 72, 113-139.

Deuschl, G., Bain, P., and Brin, M. (1998). Consensus statement of the movement disorder society on tremor. Ad hoc Scientific Committee. Mov. Disord. 13(Suppl. 3), 2-23.

Deuschl, G., Raethjen, J., Hellriegel, H., and Elble, R. (2011). Treatment of patients with essential tremor. Lancet Neurol. 10, 148-161.

Di Pauli, F., Reindl, M., Ehling, R., Schautzer, F., Gneiss, C., Lutterotti, A., O’Reilly, E., Munger, K., Deisenhammer, F., Ascherio, A., and Berger, T. (2008). Smoking is a risk factor for early conversion to clinically definite multiple sclerosis. Mult. Scler. 14, 1026-1030.

Diaz, N. L., and Waters, C. H. (2009). Current strategies in the treatment of Parkinson's disease and a personalized approach to management. Expert Rev. Neurother. 9, 1781-1789.

Dlugos, C. A. (2008). Ethanol-related increases in degenerating bodies in the Purkinje neuron dendrites of aging rats. Brain Res. 1221, 98-107.

Dogu, O., Sevim, S., Camdeviren, H., Sasmaz, T., Bugdayci, R., Aral, M., Kaleagasi, H., Un, S., and Louis, E. D. (2003). Prevalence of essential tremor: door-todoor neurologic exams in Mersin Province, Turkey. Neurology 61, 1804-1806.

Elble, R. J. (2000). Diagnostic criteria for essential tremor and differential diagnosis. Neurology 54, S2-S6.

Emerich, D. F. (2001). Neuroprotective possibilities for Huntington's disease. Expert Opin. Biol. Ther. 1, 467-479.

Erickson-Davis, C. R., Faust, P. L., Vonsattel, J. P., Gupta, S., Honig, L. S., Louis, E. D. (2010). "Hairy baskets" associated with degenerative Purkinje cell changes in essential tremor. J. Neuropathol. Exp. Neurol. 69, 262-271.

Fogel, B. L., and Perlman, S. (2006). An approach to the patient with lateonset cerebellar ataxia. Nat. Clin. Pract. Neurol. 2, 629-635.

Gasparini, M., Bonifati, V., Fabrizio, E. Fabbrini, G., Brusa, L., Lenzi, G. L. and Meco, G. (2001). Frontal lobe dysfunction in essential tremor: a preliminary study. J. Neurol. 248, 399-402.

Gironell, A. (2007). Therapeutical strategies for essential tremor. Med. Clin. (Barc.) 129, 632-637.

Gironell, A., Kulisevsky, J., Barbanoj, M., Lopez-Villegas, D., Hernandez, G., and Pascual-Sedano, B. (1999). A randomized placebo-controlled comparative trial of gabapentin and propranolol in essential tremor. Arch. Neurol. 56, 475-480.

Gironell, A., Kulisevsky, J., PascualSedano, B., and Flamarich, D. (2006). Effect of amantadine in essential tremor: a randomized, placebo-controlled trial. Mov. Disord. 21, 441-445.

Gironell, A., Martinez-Corral, M., Pagonabarraga, X., and Kulisevsky, J. (2008). Tiagabine for essential tremor: an open-label trial. Mov. Disord. 23, 1955-1956.

Handforth, A., Martin, F. C., Kang, G. A., and Vanek, Z. (2009). Zonisamide for essential tremor: an evaluator-blinded study. Mov. Disord. 24, 437-440.

Hariz, G. M., Bergenheim, A. T., Hariz, M. I., and Lindberg, M. (1998). Assessment of ability/disability in patients treated with chronic thalamic stimulation for tremor. Mov Disord. 13, 78-83.

Hariz, G. M., Blomstedt, P., and Koskinen, L. O. (2008). Long-term effect of deep brain stimulation for essential tremor on activities of daily living and health-related quality of life. Acta Neurol. Scand. 118, 387-394.

Hariz, G. M., Lindberg, M., and Bergenheim, A. T. (2002). Impact of thalamic deep brain stimulation on disability and health-related quality of life in patients with essential tremor. J. Neurol. Neurosurg. Psychiatr. 72, 47-52.

Hart, R. G., Pearce, L. A., Ravina, B. M., Yaltho, T. C., and Marler, J. R. (2009). Neuroprotection trials in Parkinson's disease: systematic review. Mov. Disord. 24, 647-654.

Helmich, R. C., Janssen, M. J., Oyen, W. J., Bloem, B. R., and Toni, I. (2011). Pallidal dysfunction drives a cerebellothalamic circuit into Parkinson tremor. Ann. Neurol. 69, 269-281.

Henriksen, A. L., St Dennis, C., Setter, S. M., and Tran, J. T. (2006). Dementia with lewy bodies: therapeutic opportunities and pitfalls. Consult. Pharm. 21, 563-575.

Hersch, S. M., and Rosas, H. D. (2008). Neuroprotection for Huntington's disease: ready, set, slow. Neurotherapeutics $5,226-236$.

Hubble, J. P., Busenbark, K. L., Wilkinson, S., Pahwa, R., Paulson, G. W., Lyons, K., and Koller, W. C. (1997). Effects of thalamic deep brain stimulation based on tremor type and diagnosis. Mov. Disord. 12, 337-341.

Ishihara, L., and Brayne, C. (2006). What is the evidence for a premorbid parkinsonian personality: a systematic review. Mov. Disord. 21, 1066-1072.

Jain, S., Lo, S. E., and Louis, E. D. (2006). Common misdiagnosis of a common neurological disorder: how are we misdiagnosing essential tremor? Arch. Neurol. 63, 1100-1104.

Karhunen, P. J., Erkinjuntti, T., and Laippala, P. (1994). Moderate alcohol consumption and loss of cerebellar Purkinje cells. BMJ 308, 1663-1667.

Karran, E., and Palmer, A. M. (2007). Neurodegenerative disorders and their treatment. Drug News Perspect. 20, 407-412.

Kieburtz, K., and Ravina, B. (2007). Why hasn't neuroprotection worked in Parkinson's disease? Nat. Clin. Pract. Neurol. 3, 240-241.

Klafki, H. W., Staufenbiel, M., Kornhuber, J., and Wiltfang, J. (2006). Therapeutic approaches to Alzheimer's disease. Brain 129, 2840-2855.

Kluger, B. M., Klepitskaya, O., and Okun, M. S. (2009). Surgical treatment of movement disorders. Neurol. Clin. 27, 633-677. 
Koeppen, A. H. (2005). The pathogenesis of spinocerebellar ataxia. Cerebellum 4, 62-73.

Kondziolka, D., Ong, J. G., Lee, J. Y., Moore, R. Y., Flickinger, J. C., and Lunsford, L. D. (2008). Gamma knife thalamotomy for essential tremor. $J$. Neurosurg. 108, 111-117.

Kotseva, K., Wood, D., De Backer, G., De Bacquer, D., Pyorala, K., and Keil, U. (2009). Cardiovascular prevention guidelines in daily practice: a comparison of EUROASPIRE I, II, and III surveys in eight European countries. Lancet 373, 929-940.

Kuo, S. H., Erickson-Davis, C., Gillman, A., Faust, P. L., and Vonsattel, J. P., and Louis, E. D. (2011). Increased number of heterotopic Purkinje cells in essential tremor. J. Neurol. Neurosurg. Psychiatr. 82, 1038-1040.

Lee, K. S., Kim, J. S., Kim, J. W., Lee, W. Y., Jeon, B. S., and Kim, D. (2003). A multicenter randomized crossover multiple-dose comparison study of arotinolol and propranolol in essential tremor. Parkinsonism Relat. Disord. 9, 341-347.

Leroi, I., O'Hearn, E., Marsh, L., Lyketsos, C. G., Rosenblatt, A., Ross, C. A., Brandt, J., and Margolis, R. L. (2002). Psychopathology in patients with degenerative cerebellar diseases: a comparison to Huntington's disease. Am. J. Psychiatry 159, 1306-1314.

Lombardi, W. J., Woolston, D. J., Roberts, J. W., and Gross, R. E. (2001). Cognitive deficits in patients with essential tremor. Neurology 57 , 785-790.

Lorenz, D., Schwieger, D., Moises, H., and Deuschl, G. (2006). Quality of life and personality in essential tremor patients. Mov. Disord. 21, 1114-1118.

Louis, E. D. (2009). Essential tremors: a family of neurodegenerative disorders? Arch. Neurol. 66, 1202-1208.

Louis, E. D., Applegate, L. M., and Rios, E. (2007a). ICD-9 CM Code 333.1 as an identifier of patients with essential tremor: a study of the positive predictive value of this code. Neuroepidemiology 28, 181-185.

Louis, E. D., Benito-Leon, J., Ottman, R., and Bermejo-Pareja, F. (2007b). A population-based study of mortality in essential tremor. Neurology 69 , 1982-1989.

Louis, E. D., Faust, P. L., Vonsattel, J. P., Honig, L. S., Rajput, A., Robinson, C. A., Pahwa, R., Lyons, K. E., Ross, G. W., Borden, S., Moskowitz, C. B., Lawton, A., and Hernandez, N. (2007c). Neuropathological changes in essential tremor: 33 cases compared with 21 controls. Brain 130, 3297-3307.
Louis, E. D., Benito-Leon, L. J., and Bermejo-Pareja, F. (2007d). Self-reported depression and anti-depressant medication use in essential tremor: cross-sectional and prospective analyses in a population-based study. Eur. J. Neurol. 14, 1138-1146.

Louis, E. D., Barnes, L., Albert, S. M., Cote, L., Schneier, F. R., Pullman, S. L., and Yu, Q. (2001). Correlates of functional disability in essential tremor. Mov. Disord. 16, 914-920.

Louis, E. D., Benito-Leon, J., and Bermejo-Pareja, F. (2009a). Population-based study of baseline ethanol consumption and risk of incident essential tremor. J. Neurol. Neurosurg. Psychiatr. 80, 494-497.

Louis, E. D., Frucht, S. J., and Rios, E. (2009b). Intention tremor in essential tremor: prevalence and association with disease duration. Mov. Disord. 24, 626-627.

Louis, E. D., Thawani, S. P., and Andrews, H. F. (2009c). Prevalence of essential tremor in a multiethnic, community-based study in northern Manhattan, New York, NY. Neuroepidemiology 32, 208-214.

Louis, E. D., Ford, B., and Frucht, S. (2003). Factors associated with increased risk of head tremor in essential tremor: a communitybased study in northern Manhattan. Mov. Disord. 18, 432-436.

Louis, E. D., Honig, L. S., Vonsattel, J. P., Maraganore, D. M., Borden, S., and Moskowitz, C. B. (2005). Essential tremor associated with focal nonnigral Lewy bodies: a clinicopathologic study. Arch. Neurol. 62, 1004-1007.

Louis, E. D., Ottman, R., Ford, B., Pullman, S., Martinez, M., Fahn, S., and Hauser, W. A. (1997). The Washington Heights-Inwood Genetic Study of Essential Tremor: methodologic issues in essential-tremor research. Neuroepidemiology 16, 124-133.

Louis, E. D., and Rios, E. (2009). Embarrassment in essential tremor: prevalence, clinical correlates and therapeutic implications. Parkinsonism Relat. Disord. 15, 535-538.

Louis, E. D., Rios, E., and Henchcliffe, C. (2010). How are we doing with the treatment of essential tremor (ET)? Persistence of ET patients on medication: data from 528 patients in three settings. Eur. J. Neurol. 17, 882-884.

Louis, E. D., and Vonsattel, J. P. (2007). The emerging neuropathology of essential tremor. Mov. Disord. 23, 174-182.

Louis, E. D., Vonsattel, J. P., Honig, L. S., Lawton, A., Moskowitz, C., Ford, B., and Frucht, S. (2006a). Essential tremor associated with pathologic changes in the cerebellum. Arch. Neurol. 63, 1189-1193.

Louis, E. D., Vonsattel, J. P., Honig, L. S., Ross, G. W., Lyons, K. E., and Pahwa R. (2006b). Neuropathologic findings in essential tremor. Neurology 66, 1756-1759.

Lyons, K. E., and Pahwa, R. (2008a). Deep brain stimulation and tremor. Neurotherapeutics 5, 331-338.

Lyons, K. E., and Pahwa, R. (2008b). Pharmacotherapy of essential tremor: an overview of existing and upcoming agents. CNS Drugs 22, 1037-1045.

Macias, Y., Benito-Leon, J., Louis, E. D., and Cano-Vindel, A. (2008). Anger in Parkinson's disease: a case-control study. Mov. Disord. 23, 195-199.

Mally, J., and Baranyi, M. (1994). Change in the concentrations of amino acids in cisternal CSF of patients with essential tremor. $J$. Neurol. Neurosurg. Psychiatr. 57, 1012-1013.

Mally, J., Baranyi, M., and Vizi, E. S. (1996). Change in the concentrations of amino acids in CSF and serum of patients with essential tremor. J. Neural Transm. 103, 555-560.

Mayeux, R., Stern, Y., Rosenstein, R. Marder, K., Hauser, A., Cote, L., and Fahn, S. (1988). An estimate of the prevalence of dementia in idiopathic Parkinson's disease. Arch. Neurol. 45 , 260-262.

Menza, M. (2000). The personality associated with Parkinson's disease. Curr. Psychiatry Rep. 2, 421-426.

Obwegeser, A. A., Uitti, R. J., Turk, M. F., Strongosky, A. J., and Wharen, R. E. (2000). Thalamic stimulation for the treatment of midline tremors in essential tremor patients. Neurology 54, 2342-2344.

Ondo, W. G., Jankovic, J., Connor, G. S., Pahwa, R., Elble, R., Stacy, M. A. Koller, W. C., Schwarzman, L., Wu, S. C., and Hulihan, J. F. (2006). Topiramate in essential tremor: a doubleblind, placebo-controlled trial. Neurology 66, 672-677.

Ovbiagele, B. (2010). Optimizing vascular risk reduction in the stroke patient with atherothrombotic disease. Med. Princ. Pract. 19, 1-12.

Pahwa, R., Lyons, K., Hubble, J. P., Busenbark, K., Rienerth, J. D. Pahwa, A., and Koller, W. C. (1998). Double-blind controlled trial of gabapentin in essential tremor. Mov. Disord. 13, 465-467.

Pahwa, R., Lyons, K. E., Wilkinson, S. B., Troster, A. I., Overman, J., Kieltyka, J., and Koller, W. C. (2001). Comparison of thalamotomy to deep brain stimulation of the thalamus in essential tremor. Mov. Disord. 16, 140-143.

Rains, J. C. (2008). Chronic headache and potentially modifiable risk factors: screening and behavioral management of sleep disorders. Headache 48, 32-39.

Ramadoss, J., Lunde, E. R., Chen, W. J., West, J. R., and Cudd, T. A. (2007). Temporal vulnerability of fetal cerebellar Purkinje cells to chronic binge alcohol exposure: ovine model. Alcohol. Clin. Exp. Res. 31, 1738-1745.

Rautakorpi, I. (1978). Essential Tremor. An Epidemiological, Clinical and Genetic Study. Finland: Academic Dissertation University of Turku.

Reynolds, K., Gu, D., Muntner, P., Kusek, J. W., Chen, J., Wu, X., Duan, X., Chen, C. S., Klag, M. J., Whelton, P. K., and He, J. (2007). A populationbased, prospective study of blood pressure and risk for end-stage renal disease in China. J. Am. Soc. Nephrol. 18, 1928-1935.

Rincon, F., and Louis, E. D. (2005). Benefits and risks of pharmacological and surgical treatments for essential tremor: disease mechanisms and current management. Expert Opin. Drug Saf. 4, 899-913.

Sasso, E., Perucca, E., Fava, R., and Calzetti, S. (1990). Primidone in the long-term treatment of essential tremor: a prospective study with computerized quantitative analysis. Clin. Neuropharmacol. 13, 67-76.

Schrag, A., Munchau, A., Bhatia, K. P., Quinn, N. P., and Marsden, C. D. (2000). Essential tremor: an overdiagnosed condition? J. Neurol. 247, 955-959.

Schuurman, P. R., Bosch, D. A., Bossuyt, P. M., Bonsel, G. J., van Someren, E. J., de Bie, R. M., Merkus, M. P., and Speelman, J. D. (2000). A comparison of continuous thalamic stimulation and thalamotomy for suppression of severe tremor. N. Engl. J. Med. 342, 461-468.

Shill, H. A., Adler, C. H., Sabbagh, M. N., Connor, D. J., Caviness, J. N., Hentz, J. G., and Beach, T. G. (2008). Pathologic findings in prospectively ascertained essential tremor subjects. Neurology 70, 1452-1455.

Shill, H. A., Bushara, K. O., Mari, Z., Reich, M., and Hallett, M. (2004). Open-label dose-escalation study of oral 1-octanol in patients with essential tremor. Neurology 62, 2320-2322.

Singer, C., Sanchez-Ramos, J., and Weiner, W. J. (1994). Gait abnormality in essential tremor. Mov. Disord. 9, 193-196. 
Song, I. U., Kim, J. S., Lee, S. B., Ryu, S. Y., An, J. Y., Kim, H. T., Kim, Y. I., and Lee, K. S. (2008). Effects of zonisamide on isolated head tremor. Eur. J. Neurol. 15, 1212-1215.

Stern, Y., Marder, K., Tang, M. X., and Mayeux, R. (1993). Antecedent clinical features associated with dementia in Parkinson's disease. Neurology 43, 1690-1692.

Stolze, H., Petersen, G., Raethjen, J., Wenzelburger, R., and Deuschl, G. (2001). The gait disorder of advanced essential tremor. Brain 124, 2278-2286.

Stout, J. C., Rodawalt, W. C., and Siemers, E. R. (2001). Risky decision making in Huntington's disease. J. Int. Neuropsychol. Soc. 7, 92-101.

Tan, E. K., Lee, S. S., Fook-Chong, S., and Lum, S. Y. (2008). Evidence of increased odds of essential tremor in Parkinson's disease. Mov. Disord. 23, 993-997.

Thanvi, B., Lo, N., and Robinson, T. (2006). Essential tremor-the most common movement disorder in older people. Age Ageing 35, 344-349.

Thawani, S. P., Schupf, N., and Louis, E. D. (2009). Essential tremor is associated with dementia: prospective population-based study in New York. Neurology 73, 621-625.
Thompson, C., Lang, A., Parkes, J. D., and Marsden, C. D. (1984). A double-blind trial of clonazepam in benign essential tremor. Clin. Neuropharmacol. 7, 83-88.

Traub, R. E., Gerbin, M., Mullaney, M. M., and Louis, E. D. (2010). Development of an essential tremor embarrassment assessment. Parkinsonism Relat. Disord. 16, 661-665.

Troster, A. I., Fields, J. A., Pahwa, R., Wilkinson, S. B., Strait-Troster, K. A., Lyons, K., Kieltyka, J., and Koller, W. C. (1999). Neuropsychological and quality of life outcome after thalamic stimulation for essential tremor. Neurology 53, 1774-1780.

Troster, A. I., Pahwa, R., Fields, J. A., Tanner, C. M., and Lyons, K. E. (2005). Quality of life in essential tremor questionnaire (QUEST): development and initial validation. Parkinsonism Relat. Disord. 11, 367-373.

Troster, A. I., Woods, S. P., Fields, J. A., Lyons, K. E., Pahwa, R., Higginson, C. I., and Koller, W. C. (2002). Neuropsychological deficits in essential tremor: an expression of cerebellothalamo-cortical pathophysiology? Eur. J. Neurol. 9, 143-151.

Ushe, M., Mink, J. W., Revilla, F. J., Wernle, A., Schneider Gibson, P., McGee-Minnich, L., Hong, M., Rich, K. M., Lyons, K. E., Pahwa, R. and Perlmutter, J. S. (2004). Effect of stimulation frequency on tremor suppression in essential tremor. Mov Disord. 19, 1163-1168.

Voss, T., and Ravina, B. (2008). Neuroprotection in Parkinson's disease: myth or reality? Curr. Neurol. Neurosci. Rep. 8, 304-309.

Winkler, G. F., and Young, R. R. (1971) The control of essential tremor by propranolol. Trans. Am. Neurol. Assoc. 96, 66-68.

Young, R. R. (2002). Effective treatment for essential tremor. Ann. Neurol. 51 407.

Zesiewicz, T. A., Elble, R., Louis, E. D., Hauser, R. A., Sullivan, K. L., Dewey, R. B. Jr., Ondo, W. G., Gronseth, G. S., and Weiner, W. J. (2005). Practice parameter: therapies for essential tremor: report of the Quality Standards Subcommittee of the American Academy of Neurology. Neurology 64, 2008-2020.

Zesiewicz, T. A., Encarnacion, E., and Hauser, R. A. (2002). Management of essential tremor. Curr. Neurol. Neurosci. Rep. 2, 324-330.

Zesiewicz, T. A., Ward, C. L., Hauser R. A., Sanchez-Ramos, J., Staffetti, J. F., and Sullivan, K. L. (2007). A double-blind placebo-controlled trial of zonisamide (zonegran) in the treatment of essential tremor. Mov. Disord. 22, 279-282.

Zoccolella, S., Santamato, A., and Lamberti, P. (2009). Current and emerging treatments for amyotrophic lateral sclerosis. Neuropsychiatr. Dis. Treat. 5, 577-595.

Conflict of Interest Statement: The author declares that the research was conducted in the absence of any commercial or financial relationships that could be construed as a potential conflict of interest.

Received: 12 September 2011; paper pending published: 11 November 2011; accepted: 28 December 2011; published online: 13 January 2012.

Citation: Louis ED (2012) Treatment of essential tremor: are there issues we are overlooking? Front. Neur. 2:91. doi: 10.3389/fneur.2011.00091

This article was submitted to Frontiers in Movement Disorders, a specialty of Frontiers in Neurology.

Copyright (c) 2012 Louis. This is an open-access article distributed under the terms of the Creative Commons Attribution Non Commercial License, which permits non-commercial use, distribution, and reproduction in other forums, provided the original authors and source are credited. 